GRASAS Y ACEITES 70 (4)

October-December 2019, e330

ISSN-L: 0017-3495

https://doi.org/10.3989/gya.1167182

\title{
Characterization of different ozonized sunflower oils II. Triacylglycerol condensation and physical properties
}

\author{
O.E. Ledea-Lozano ${ }^{\mathrm{a}}$, L.A. Fernández-García ${ }^{\mathrm{a}}$, D. Gil-Ibarra ${ }^{\mathrm{a}}$, M.Á. Bootello ${ }^{\mathrm{b}}$, \\ R. Garcés ${ }^{c}$, E. Martínez-Force ${ }^{c}$ and J.J. Salas ${ }^{c}$, \\ ${ }^{a}$ CNIC Ave 25 y 158 N0 15202. Cubanacan, Playa. Apartado Postal 6414, Ciudad de la Habana, Cuba, CP:12100. \\ ${ }^{b}$ Bunge Ibérica, Carrer de la Constitució, 1, 08960 Sant Just Desvern, Barcelona, Spain. \\ 'Instituto de la Grasa, CSIC. Ctra. Utrera Km 1, 41013, Sevilla, Spain. \\ Corresponding author: jjsalas@ig.csic.es
}

Submitted: 06 November 2018; Accepted: 22 January 2019; Published online: 24 July 2019

\begin{abstract}
SUMMARY: Within the chemical transformations that vegetable oils undergo, oxidative reactions are one of the most widely studied. During the process of oxidation oils react with oxygen in their different forms to produce a large variety of chemical species that alter their chemical and physical properties. This work is the second of a series of two in which the action of ozone on different sunflower oils was investigated. Ozone reacts with double bonds of unsaturated fatty acids which produce different peroxidated species. The presence of altered triacylglycerol (TAG) increases the polarity of the vegetable oils and induces changes in their physical properties. Moreover, peroxygenation alters the aggregation of TAGs, favoring the formation of dimers or oligomers that can substantially change the melting and crystallization profiles of these oils. In the present work the effect of ozonation on four different sunflower oils was studied: common sunflower, high oleic sunflower and two highly saturated sunflower oils, high palmitic and stearic in a high oleic background. Furthermore, the species of TAGs from the different oils that were affected by the ozone oxidative attack were studied. The formation of polar compounds and TAG aggregates were investigated as well as the effect caused by them on the physical properties of the oils as studied through differential scanning calorimetry.
\end{abstract}

KEY WORDS: Differential scanning calorimetry; Melting profile; Ozonation; Peroxides; Polar lipids; Sunflower oil; Triacylglycerols

RESUMEN: Caracterización de diferentes aceites de girasol ozonizados II. Condensación de triacilgliceroles y propiedades físicas. Dentro de las transformaciones químicas que experimentan los aceites vegetales, las reacciones oxidativas son de las más ampliamente estudiadas. Durante el proceso de oxidación los aceites reaccionan con el oxígeno en sus distintas formas para producir una amplia variedad de especies químicas que alteran sus propiedades físico-químicas. Este trabajo es el segundo de una serie de dos en los cuales se investigó la acción del ozono sobre diferentes aceites de girasol. El ozono reacciona con los dobles enlaces de los ácidos grasos insaturados produciendo diferentes especies peroxigenadas. La presencia de triacilgliceroles (TAG) alterados incrementa la polaridad de los aceites vegetales y producen cambios en sus propiedades físicas. Además, la peroxidación altera el nivel de agregación de los TAGs, favoreciendo la formación de dímeros u oligómeros que cambian de manera importante sus perfiles de fusión y cristalización. En este trabajo se estudió el efecto de la ozonización de cuatro aceites diferentes: girasol común, alto oleico, y dos aceites alto saturado, alto palmítico y esteárico, en fondo alto oleico. Así mismo, se estudiaron las especies de TAGs de estos aceites que fueron afectadas por el ataque oxidativo del ozono. Se investigaron por lo demás la formación de compuestos polares y TAGs agregados, además del efecto causado por ellos en sus propiedades físicas mediante estudios de calorimetría diferencial de barrido.

PALABRAS CLAVE: Aceite de girasol; Calorimetría diferencial de barrido; Lípidos polares; Ozonización; Perfil de fusión; Peróxidos; Triacilglicerol

ORCID ID: Ledea-Lozano OE https://orcid.org/0000-0001-8521-2747, Fernández-García LA https://orcid.org/00000002-1043-5505, Gil-Ibarra D https://orcid.org/0000-0002-1561-6495, Bootello MÁ https://orcid.org/0000-0003-49622751, Garcés R https://orcid.org/0000-0003-2571-8644, Martínez-Force E https://orcid.org/0000-0001-5324-9537, Salas JJ https://orcid.org/0000-0002-3259-2587

Citation/Cómo citar este artículo: Ledea-Lozano OE, Fernández-García LA, Gil-Ibarra D, Bootello MÁ, Garcés R, Martínez-Force E, Salas JJ. 2019. Characterization of different ozonized sunflower oils II. Triacylglycerol condensation and physical properties. Grasas Aceites 70 (4), e330. https://doi.org/10.3989/gya.1167182

Copyright: (02019 CSIC. This is an open-access article distributed under the terms of the Creative Commons Attribution 4.0 International (CC BY 4.0) License. 


\section{INTRODUCTION}

Vegetable oils consist of a matrix of triacylglycerols (TAGs) plus minor compounds. TAGs are esters of fatty acids with glycerol and account for more than the $95 \%$ of the oils. Therefore, oil properties are strongly dependent on their fatty acid composition and the distribution of them among the different TAG species (Harwood et al., 2007). The most direct modifications that vegetable oils can experiment are hydrolytical and oxidative. The hydrolysis of oils involves the breakage of TAGs which releases free fatty acids that increase the oils' acidity values and promote the formation of soaps and emulsions. Oxidation involves the reaction of fatty acid chains with oxygen giving way to a large variety of oxygenated compounds (Min and Boff, 2002). The most commonly studied oil oxidation process is autooxidation, which involves the reaction of fatty acid moieties with molecular oxygen through a free radical based chain reaction mechanism. This mechanism involves the initiation of the reaction by the homolytic abduction of a hydrogen atom from fatty acids, followed by the reaction propagation after the formation of peroxide radicals by reaction with atmospheric oxygen. Propagation involves the accumulation of hydroperoxides that can decompose to carbonyl compounds. The rates of autooxidation are dependent on the presence of initiators (metals, peroxides) and the concentration of polyunsaturated fatty acids, due the fact that they are able to stabilize free radical intermediates. The termination reactions usually involve the blockage of free radicals by several mechanisms (Chloe and Min, 2006). Among them, we can find the formation of TAG dimers or oligomers through the formation of $\mathrm{C}-\mathrm{C}$ or peroxide bridges from the corresponding free radical species. Therefore, oil oxidation usually involves changes in TAG aggregation. This aspect can be monitored by size-exclusion chromatography (Márquez-Ruiz et al., 1990) and it is important for determining the quality of used oils. For example, frying oils should not have more than $25 \%$ polymerized TAGs to be considered admissible for human food consumption (Gertz, 2000). Furthermore, the polymerization of highly unsaturated vegetable oils is also used for the fabrication of natural plastics like linoleum (Sharmin et al., 2015).

The mechanism of oxidation that takes place during vegetable oil ozonation differs from the one in autooxidation. Ozone is an oxidant which is stronger than molecular oxygen and quickly attacks both carbons in double bonds in unsaturated fatty acids producing unstable 1,2,3-trioxolanes or primary ozonides. These intermediates are very unstable and decompose forming a carbonyl compound (aldehyde) and carbonyl oxide or zwitterion (Criegee intermediate). From this moment and taking into account the reaction conditions, different pathways can be taken and therefore different reaction products can be obtained (Bailey et al., 1978). The most important concept of the Criegee mechanism from this point of view is precisely, the possibility of explaining the formation of all the peroxidic products of the ozonolysis of the unsaturated compounds from a single intermediate, the zwitterion of Criegee or carbonyl oxide. The different paths that could take place are competitive and in most cases lead to complex mixtures with different proportions of the products formed. If it is required to improve or increase the yields of one product in question, it is necessary to take into account a series of factors in the establishment of the reaction conditions. Among these factors are: the use or not of solvents and their type; the presence of other compounds, the temperature of the reaction; the type of reactor; the agitation of the reaction mixture, among others. (Díaz et al., 2005; Martínez Téllez et al., 2006). Classically, primary ozonides can rearrange themselves in aprotic media to give way to more stable ozonides (1,2,4 trioxolanes). In the presence of water, ozonides are split to yield carbonyl fragments plus hydroxyl-hydroperoxides. Ozonides and hydroxyl hydroperoxides can also decay into carbonyl compounds with time. The combination of two or more triglyceridic carbonyl oxides produces diperoxides and peroxidic triglyceride oligomers (Díaz et al., 2005; Martínez Téllez et al., 2006). Unlike autooxidation, the rates of ozonation are not so dependent on the presence of polyunsaturated species, but the reactions take place at similar rates to monounsaturated ones.

This work studied the rates of ozonation of sunflower oils with different fatty acid composition at different doses of applied ozone. The oils studied were common sunflower, high oleic sunflower, high stearic-high oleic sunflower and high palmitichigh oleic sunflower (Fernández-Moya et al., 2005; Fernández Martínez, et al., 1997; Garcés et al., 1989). In all cases, ozone should react with the predominant unsaturated fatty acid, linoleic or oleic depending on the composition, and their concentration substantially decreased throughout the course of ozonation with a concomitant increase in the proportion of saturated fatty acids. Therefore, the changes in the TAG aggregation of ozonized oils throughout the oxidation process were studied as well as the modification that this induced in the melting and crystallization profiles of these oils through differential scanning calorimetry (DSC) techniques. This aspect could be of importance because these oils were designed for the production of high melting point fats and pomades. The chemical and physical transformations of the different 
oils induced by ozonation were discussed in view of the results.

\section{MATERIALS AND METHODS}

\subsection{Oil ozonization procedure}

Four sunflower oils were ozonized: common sunflower from Borges Co. (Spain); high-oleic sunflower, high stearic-high-oleic sunflower and high-palmitic-high-oleic sunflower supplied by the Instituto de la Grasa (Spain). The respective Sunflower oil $(100 \mathrm{~mL})$ was placed in a jacketed bubbling reactor at the controlled temperature of $25 \pm 0.1{ }^{\circ} \mathrm{C}$. A mixture of $\mathrm{O}_{3} / \mathrm{O}_{2}$ was introduced into the reactor at a flow rate of $30 \mathrm{~L} / \mathrm{h}$ during the reaction time $(2.75 \mathrm{~h})$. Samples corresponding to ozone mean doses of $0.45 ; 0.90$; and $1,33 \mathrm{~mol}$ of ozone per liter of oil were taken every 55 minutes. Ozone was generated in an AQOZO ozone generator (Havana, Cuba) and its concentration was determined by measuring the absorbance at $254 \mathrm{~nm}$ in an Ultraspec III spectrophotometer (Pharmacia LKB, Uppsala, Sweden). The ozone concentration at the exit of the reactor was measured every 5 minutes. Three ozonation processes were carried out for each studied sunflower oil.

\subsection{Isolation of neutral and polar lipid fraction}

The polar lipid fraction containing the oxidized lipids from different ozonized oils was separated by applying the Standard method (Waltking and Wessels, 1981) scaled down for $1 \mathrm{~g}$ of sample. $25 \mathrm{~g}$ of silica gel were hydrated with $5 \%$ distilled water in a rotavapor for 30 minutes. The mixture was then suspended in Hexane/ethyl ether 87:13 v:v to construct a column in the same solvent. $1 \mathrm{~g}$ of ozonized oil was dissolved in $2 \mathrm{~mL}$ of hexane and loaded onto the column. Then the column was eluted with $125 \mathrm{~mL}$ of Hexane/ethyl ether 87:13 v:v and the flow containing the neutral lipids was collected. The column was eluted with an additional $125 \mathrm{~mL}$ of the same solvent and both fractions were combined to form neutral lipid one. The polar lipids were then eluted with a volume of $150 \mathrm{~mL}$ of pure ethyl ether. The fractions were transferred to tared flasks and the solvent was removed in rotavapor. The resulting residues were weighed, dissolved in $5 \mathrm{~mL}$ trichoromethane and stored at $-20^{\circ} \mathrm{C}$ under nitrogen atmosphere.

\subsection{Analysis of TAG dimers and oligomers by size exclusion HPLC}

Oil or polar fraction samples were dissolved in tetrahydrofuran (THF) and filtered through $0.22 \mu \mathrm{m}$ membranes. They were then injected into the HPLC system for size exclusion analysis using the method reported by Márquez-Ruíz et al., (1990). The HPLC system consisted of a Waters 2695 separation module endowed with a 2420 ELS detector. Two columns connected in series were used for the analysis, the first one was a Waters $100 \AA$ A Ultrastyragel THF $(7.8 \times 300 \mathrm{~mm})$ column and the second was a Waters $500 \AA$ Ultrastyragel THF $(7.8 \times 300 \mathrm{~mm})$. THF in isocratic regime at $0.5 \mathrm{~mL} / \mathrm{min}$ was used as the mobile phase. The system was calibrated using an autooxidized sunflower oil of known composition.

\subsection{Analysis of triacylglycerols}

The analysis of TAGs in the neutral lipid fraction was carried out by gas chromatography in an Agilent 6890 gas chromatograph (Palo Alto, CA) using a Quadrex Aluminium-Clad 400-65HT (30 m length, $0.25 \mathrm{~mm}$ i.d., $0.1 \mu \mathrm{m}$ film thickness: Woodbridge, CT, USA) capillary column and flame ionization detector (FID). The working temperatures of the injection and detection were 360 and $370{ }^{\circ} \mathrm{C}$, respectively. The split ratio of injection used was 1:80, with hydrogen as the carrier gas at a linear rate of $50 \mathrm{~cm} / \mathrm{s}$. The method used was isothermal at $335{ }^{\circ} \mathrm{C}$, with a head pressure gradient from 100 to $180 \mathrm{kPa}$. The amount of total TAGs injected should not be higher than $2.5 \mu \mathrm{g}$. In these conditions the peaks were identified according to their retention times, which were compared with those in our database, obtained from the analysis of oils of known composition. After integration the percentages of each TAG were corrected according to the response factors calculated by Carelli and Cert (1993).

\subsection{Differential scanning calorimetry}

The melting and crystallization profiles of the different oils were determined by differential scanning calorimetry (DSC) using a Q2000 V23.5 scanner (TA instruments, New Castle, DE, USA). The results were processed using the TA analysis software provided by the manufacturer. This instrument was calibrated prior to use with indium, azobenzene, and undecane purchased from Sigma-Aldrich (Madrid, Spain). Nitrogen was used to purge the system. Samples were prepared by pipetting 6-8 $\mathrm{mg}$ of the oils into aluminium pans, and weighing them using a Sartorius M2P electronic microbalance (Sartorius AG, Goettingen, Germany). The pans were then sealed and balanced calorimetrically, using an empty sealed capsule as the reference. The melting profile of the oils was determined by heating the samples at $50{ }^{\circ} \mathrm{C}$ and holding for $10 \mathrm{~min}$ (in order to delete the thermal memory), then cooling to $-80{ }^{\circ} \mathrm{C}$ at a rate of $10{ }^{\circ} \mathrm{C} / \mathrm{min}$ and held for 180 minutes. Finally, a heating ramp of $5^{\circ} \mathrm{C} / \mathrm{min}$ up to $50^{\circ} \mathrm{C}$ was applied to obtain the melting thermograms. The crystallization 
profile was also obtained by completely melting the oils at $50^{\circ} \mathrm{C}$ for $10 \mathrm{~min}$, and decreasing the temperature to $-80^{\circ} \mathrm{C}$ at a rate of $10^{\circ} \mathrm{C} /$ minute.

\subsection{Statistical analysis}

Values of different magnitudes represented the average of three independent determinations plus or minus standard deviation.

\section{RESULTS AND DISCUSSION}

\subsection{TAG composition of the ozonized oils}

The properties of oils not only depend on their fatty acid composition but also on the distribution of those fatty acids throughout the different TAG species. So, it is important to know the TAG composition of the different oils used as substrates in ozonation reactions because it is a factor which somewhat determines the distribution of the oxygenated functions and their later changes in aggregation. The TAG compositions of the oils used in this work were substantially different from each other (Table 1). The TAG species were named according to their fatty acid moieties by assigning letters or pairs of letters to each one (P: palmitic; Po: palmitoleic; O: oleic; As: asclepic; St: stearic; L: linoleic; A: Arachidic; B: behenic). Common sunflower oil displayed high levels of LLL and LLO, which accounted for up to $56 \%$ of the total TAG species found in that oil. Saturated fatty acids were present mainly in monosaturated TAG species (mostly PLL and StLL), and only traces of disaturated TAGs were found. The high-oleic oil differed from the other oils in that it contained a single predominant TAG specie that was glyceryl-trioleate or triolein (OOO), accounting for $64.8 \%$ of the total TAG composition. Saturated fatty acids were similarly distributed as in the case of common sunflower, forming monosaturated TAG species. The high saturated oils, high-stearic and high-palmitic, displayed similar fatty acid distributions. Thus, saturated fatty acids in sunflower oil are mostly bound to the sn-1,3 positions in a very low proportion $(<0.5 \%)$ and are bound to the sn-2 position of the TAGs. Thus, no tri-saturated TAGs were detected in these oils, and the predominant species were mono-saturated like StOO or POO $(33 \%$ and $28.9 \%$ respectively), which were the saturated acyl moieties in the external sn-1,3 positions. Disaturated TAG species were also present, although they represent a minor fraction of the oils. The presence of n-7 unsaturated fatty acids (Po and As) in the TAG of high palmitic oil caused the number of species found in the ozonized oil to be higher. This fact is also related to the different physico - chemical properties found for this ozonized oil with respect to the others.

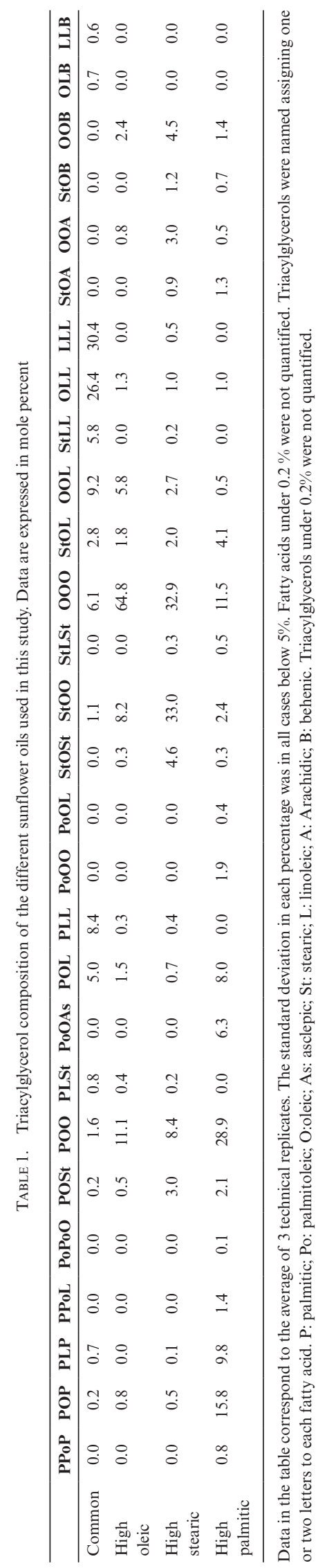




\subsection{Accumulation of polar lipids and changes in triacylglycerol species}

During the process of ozonation, oxygen was incorporated into the TAG fraction in the form of oxygenated compounds that can be evaluated globally by determining the percentage of polar lipids in the oil. This was carried out by separating the neutral fraction from the polar fraction by liquid chromatography on hydrated silica gel. The neutral and polar fractions were quantified by weight, which resulted in a linear increment in the content of polar lipids that was in accordance with the ozone doses applied. (Figure 1). Thus, the polar lipid contained the TAGs that were peroxidated by the action of the ozone and the carbonyl moieties that were formed by ozonide disruption. On the contrary the neutral lipid fraction included the TAGs that were not oxidized throughout the reaction course, because the reaction was conducted as a partial ozonation of the unsaturated TAG. Again, the profile of polar lipid accumulation was very different from what would be expected from an autooxidation process, especially because of high reaction rates and product accumulation. The content of polar lipids reached high proportions, accounting for almost $80 \%$ of the total oil mass at the end of the experiment. According to the profiles of the different oils the shape of the polar lipid accumulation curve was similar for all of them, but an important difference can be observed at the end of the experiment. Oils containing higher levels of saturated fatty acids, for example, high stearic and high palmitic oils, displayed contents of polar lipids which were significantly higher than common and oleic sunflower. This result could seem unexpected



FIGURE 1. Accumulation of polar lipids during the course of ozonation of different sunflower oils. Data represents the percentage of polar lipids at different stages of ozonation. Data correspond to common sunflower (black bars), high oleic sunflower (white bars), high stearic sunflower (light grey bars) and high palmitic sunflower (dark grey bars). Data represent average data from three determinations plus or minus standard deviation. but it can be explained by looking at the fatty acid distribution of the different oils. Common and high oleic oils contain TAGs with high levels of unsaturation like LLL, LLO, LOO or OOO, in which all the esterified fatty acids are unsaturated. These TAGs are able to react with several molecules of ozone, resulting in a concentration of new oxygenated groups on them. Highly saturated oils displayed fewer targets for oxidation which were more widely distributed throughout the TAG species, which caused a higher proportion of altered TAGs at high levels of ozonation, which produced an increment in the total polar lipids in such conditions.

\subsection{Changes in the composition of neutral lipids}

The neutral lipid fractions obtained represented the fraction of oil that did not react with ozone. Therefore, the composition of this fraction revealed the TAG species which were more reactive within each oil, along with other aspects of the reaction of oxidation with ozone. The sunflower oils treated with increasing amounts of ozone changed their TAG composition according to Figure 2. In that figure, the percentage of the main TAG species occurring in each oil is shown at different stages of the ozonation reaction. In common sunflower the main targets of ozonation were the TAGs LLL and LLO, which decreased throughout the whole course. This result was expected due to the fact that these TAGs contain the largest amount of unsaturations, which are the groups attacked by ozone. The decrease in the proportion of these species was compensated by the increment of other ones. Looking at the compositions of these fractions, species with 4 double bonds like OOL and PLL increased very slightly throughout the course; whereas this increment was more pronounced in species with 3 or less unsaturations as in the case of $\mathrm{OOO}$ and POO. The profile of high oleic TAGs differed considerably from that observed for common sunflower. This time the main changes in composition relied on OOO, which was by far the more abundant one and represented the specie with the highest level of unsaturation after OLL and OOL, which were in much lower proportions. Monosaturated species (POO and StOO) increased their proportions very slightly throughout the course. The high stearic-high oleic oil displayed the main changes in the composition of OOO, which displayed a strong decrease throughout the course. On the contrary, the di-saturated TAGs StOSt and POSt displayed important increases in proportions. The content of the most abundant TAG StOO did not display important changes, relaying most of the oxidative attack to more unsaturated species like OOO or OOL. The high palmitic-high oleic oil contained higher levels of saturated fatty acids (31.3\% against 24.3\%; Fernández-Martínez et al., 1997), which involved lower levels of tri-unsaturated TAGs 

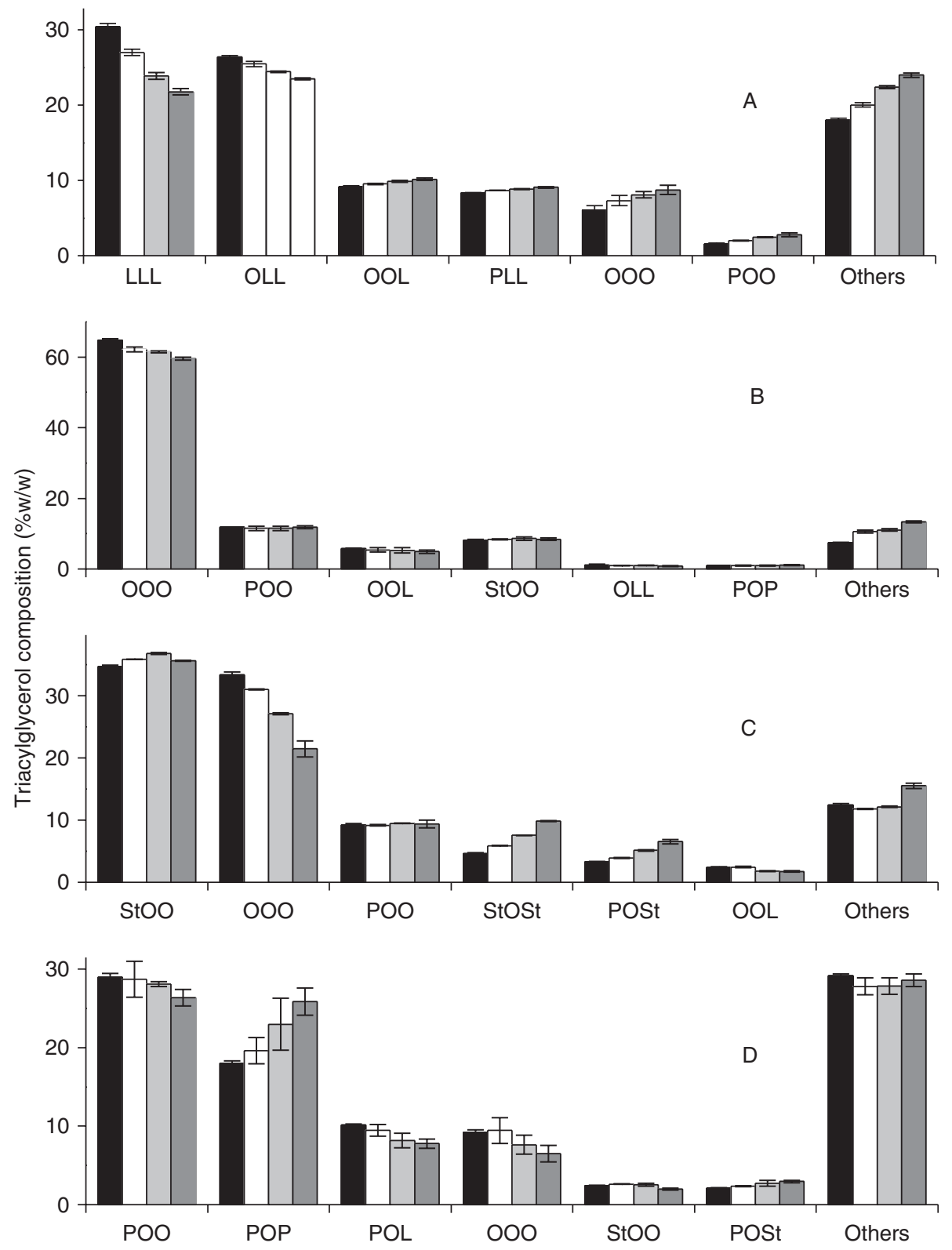

FIGURE 2. Triacylglycerol composition of the neutral fraction isolated from sunflower oils during the course of ozonation. Data correspond to initial oils (Black bars), $0.45 \mathrm{~mol} / \mathrm{L}$ ozone applied (white bars), $0.90 \mathrm{~mol} / \mathrm{L}$ ozone applied (light grey bars) and $1.33 \mathrm{~mol} / \mathrm{L}$ ozone applied (dark grey bars). Common sunflower (A), high oleic sunflower (B), High stearic sunflower (C) and high palmitic sunflower (D) oils were used as substrates. Data represent average data from three determinations plus or minus standard deviation.

like OOO. The pattern of TAG variation in this oil during the course of oxidation showed decreases in POO, POL and OOO at the expense of important increments in the proportion of POP. Thus, this oil differed from the high stearic one in that the oxidative alteration was more widely distributed throughout different TAGs; whereas in the former relied mainly on OOO. In both cases, the increase in the proportion of di-saturated TAGs was remarkable, mainly POP, StOSt and POSt, which is interesting due the fact that these TAGs possess higher melting points and their contents determine the melting profiles of many fats and oils. This result shows that these TAG species were refractory to ozone oxidation, probably because they only have a single unsaturation to be attacked and by the protective action of the saturated fatty acids esterified in the sn- 1,3 position, which probably hinder the access of the oxidant to the unsaturated fatty acid esterified in the central position of the TAG.

These results are in good agreement with the records of polar lipid in Figure 1, where, unexpectedly, 
high saturated oils displayed higher proportions of them than common or high oleic ones. Thus, in the later oils oxidation relied on fewer TAG species with higher degrees of unsaturation, able to have several double bonds ozonized. The lower level of unsaturation of the TAG species in the former oils reduced the possibility of multiple oxidative attacks in the same molecule, resulting in ozonation being extended to a broader number of TAG molecules, which on a macroscopic scale, was shown as higher proportions of total polar lipid fractions.

\subsection{Dimers, oligomers and altered triacylglycerols}

During the process of autooxidation, the production of free radical intermediates gave way to the polymerization of TAG molecules by the formation of covalent bonds through the interaction of pairs of free radicals within the reactions of termination of this chain reaction process. TAG polymerization is often monitored to follow the level of oil autooxidation but little has been studied with regard to other oxidative processes like ozonation. In the present work we studied the formation of TAG condensates, dimers and oligomers by the action of ozonation. This was done by determining the condensates in the total oil and in the polar fractions isolated from the same oils by size exclusion HPLC. Thus, by knowing the size of the polar fraction it was possible to find the proportion of dimers, oligomers and altered TAGs in the oils (Figure 3). The formation of TAG condensates started from the very beginning of the oil ozonation, as can be seen in Figure 3A, where the dimer formation followed linear patterns similar to those corresponding to the incorporation of ozone into the oils (Characterization of different ozonized sunflower oils I, in this number). This result indicated that the formation of dimers was simultaneous to the ozonation of double bonds and that it did not follow a different mechanism. Furthermore, the different oils displayed similar patterns of dimer formation, not showing significant differences throughout the course. The formation of oligomers (Figure 3B) displayed a different pattern -- it was not
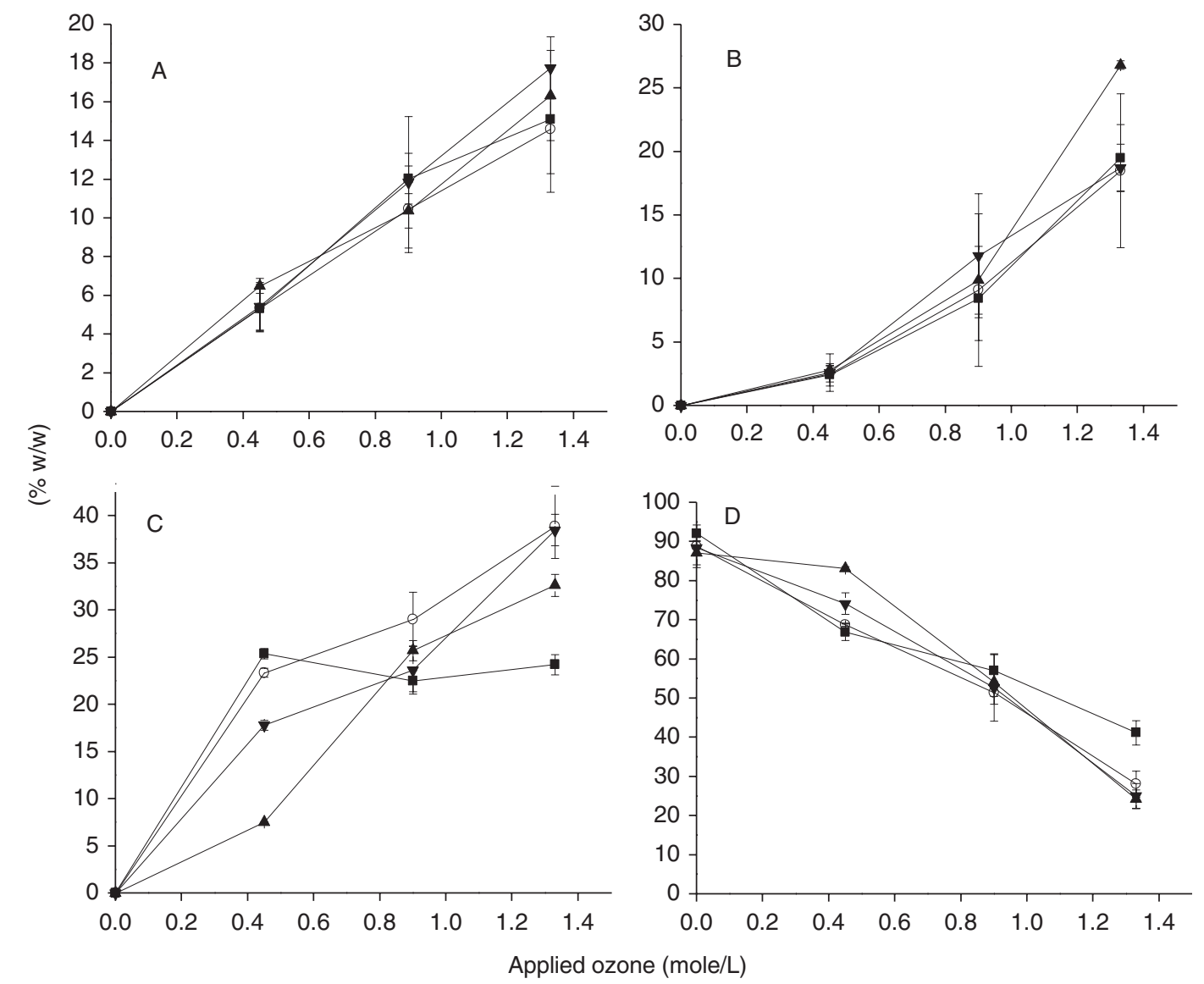

FIGURE 3. Accumulation of dimers (A), oligomers (B), altered triacylglycerol monomers (C) and non-modified triacylglycerols (D) during the course of ozonation of different sunflower oils. Data represents the increment in peroxide value against the supplied


were used as substrates. Data represent average data from three determinations plus or minus standard deviation. 
linear and displayed higher increments of formation at longer reaction times. This result was expected, due to the formation of larger molecular weight condensates, which was progressive and accelerated when dimers or small oligomers had the possibility of binding to each other. In this case only the high stearic sunflower oil displayed significant differences at the end of the course compared to the other oils. With regard to altered TAG monomers, there were interesting differences concerning the different oils. Common sunflower displayed a higher proportion of this oxidized monomer at short reaction times and became stable until the end of the course; whereas in the other lines, with high oleic backgrounds, there was a progressive increment in the altered TAGs which reached their maximal values at the end of the reaction (Figure 3C). Thus, there were important differences in the percentages of these altered TAGs at the end of the course, which were around $20 \%$ in common sunflower and between 30 and $35 \%$ for the other lines. The contents of unaltered TAGs was in agreement with this distribution, with final contents of unaltered TAGs being higher in the common sunflower oil (Figure 3D). This result can be explained from the TAG and fatty acid compositions of common sunflower oil. This oil is rich in TAGs like LLL and LLO, which contain 6 and 5 double bonds, respectively, and can react with several ozone molecules at a time, reducing the number of TAG molecules oxidized at the end of the oxidation course with the same applied doses. Also, the transference processes play and important role in the heterogeneous systems working better at the gas - liquid systems.

Theoretically, the ozonation of oils could involve the formation of TAG dimers. This process is favored when oil reacts with ozone in a neat solution. This means in the absence of solvents. These dimers are quite different from the ones produced by autooxidation, because no free radicals are involved and they present a di-peroxidic functional group as a result of a combination of two zwitterions placed near each other. The results in the present study point to di-peroxidic dimer formation, due to the detection of a linear formation of TAG dimers, concomitant with the peroxidation of the oils, which did not display an induction period which is typical of chain reaction mechanisms. (Criegee, 1975) The di-peroxidic dimers (or 1,2,4,5 tetraoxanes) formed are represented as shown in Figure 4.

\subsection{Melting and crystallization profiles of ozonized oils}

Important changes in the chemical composition of ozonized sunflower oils were observed. These changes involve an increment in the content of saturated fatty acids and derived TAG species, with carbonyl, ozonides and peroxidic functions. Moreover,

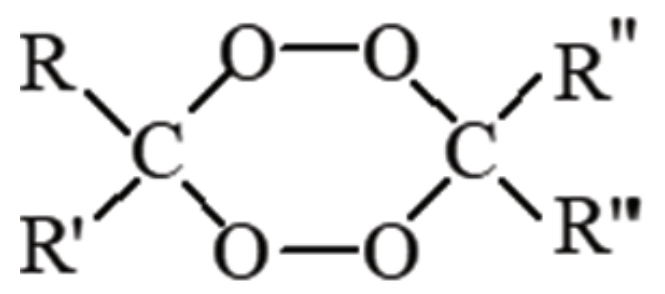

FIGURE 4. Representation of a generic diperoxidic dimer (or 1,2,4,5 tetraoxanes) where: R, R', R" y R"' are triglyceridic or $\mathrm{C} 6, \mathrm{C} 9$ lineal fragments.

the results in the preceding section point to the production of TAG condensates (peroxidic dimers) as a direct consequence of oxidation with ozone. All these chemical changes should also affect the physical properties of the ozonized oils.

Vegetable oils usually consist of a complex mix of TAGs with different melting points. This means that the oils do not have a sharp melting or crystallization point but are characterized by a certain melting or crystallization interval resulting from the successive phase changes and inter-solubility of the different TAG components into others at different temperatures. One of the most accurate techniques to measure changes in the phase transitions in oils is differential scanning calorimetry, which studies the flow or transference of heat that the samples undergo at different temperatures, revealing both phase and allotropic modifications. In the present work the effect of ozonation on the melting and crystallization profiles of different sunflower oils was investigated. Common sunflower oil is a liquid transparent oil at room temperature. The high levels of unsaturated fatty acids and TAG species like LLL or LLO cause phase changes in this oil to take place at very low temperatures (Figures 5A and 6A). Thus, the melting interval from 0 to $-50{ }^{\circ} \mathrm{C}$, displaying 5 peaks at different temperatures, probably corresponded to different TAG species with different levels of unsaturation. Second order crystalline transitions were also found in the range of very low temperatures $\left(-60\right.$ to $\left.-70{ }^{\circ} \mathrm{C}\right)$. The crystallization profile displayed an onset at $-15^{\circ} \mathrm{C}$, at which temperature the oil started to solidify. The progressive ozonation of the oil substantially changed its melting profile within the temperature range studied. Thus, the clearly defined peaks soon disappeared, resulting in a large single peak, which decreased its height, which was at its minimum at the highest stage of oxidation (Figure 5A). Interestingly, the changes in the crystallizing profile varied much less throughout the reaction, displaying the oils' similar onsets and profiles. In the case of high oleic the melting profile of the initial oil displayed a large main peak at $-10{ }^{\circ} \mathrm{C}$ which corresponded to triolein, the main TAG component in the oil. This peak broadens 

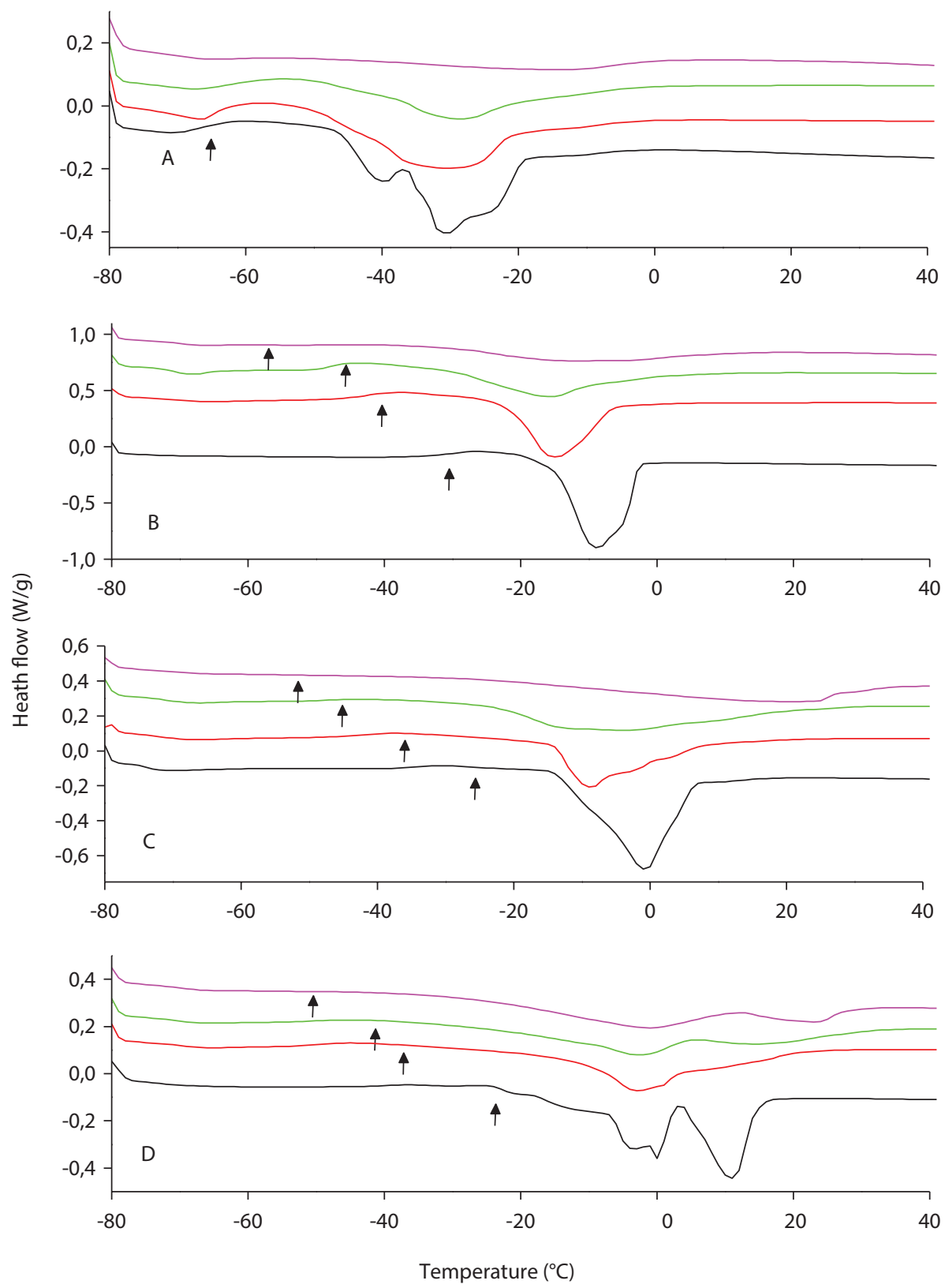

FIGURE 5. Melting curves of different sunflower oils during the process of oil ozonation obtained by differential scanning calorimetry. Data represent results obtained with common sunflower (A), high oleic sunflower (B), high stearic sunflower

(C) and high palmitic sunflower (D). Different degrees of ozonation correspond to different colors; Initial oil (black), $0.45 \mathrm{~mol} / \mathrm{L}$ (red), $0.90 \mathrm{~mol} / \mathrm{L}$ (green) and $1.33 \mathrm{~mol} / \mathrm{L}$ (purple). Arrows indicate secondary transitions.

its base and decreases its intensity throughout the course of ozonation in a way similar to the common sunflower (Figure 5B). In this case, the secondary transitions observed in the initial oil at $-30{ }^{\circ} \mathrm{C}$ took place at lower temperatures when the degree of ozonation increased. The crystallization curve of high oleic displayed a sharp signal at $-55^{\circ} \mathrm{C}$ which decreased when the oil ozonation advanced (Figure 6B). The same pattern was observed in the high saturated sunflower oils. Thus, the high stearic oil displayed a large peak, revealing the monosaturated TAGs $\left(-5^{\circ} \mathrm{C}\right)$ and triolein $\left(-10^{\circ} \mathrm{C}\right)$, which gave way to a single broad peak of lower intensity (Figure 5C). This pattern was even more obvious for the high palmitic (Figure 5D), where two clusters of peaks were clearly differentiated, probably due to the melting of di-saturated TAGs POP and POSt $\left(10^{\circ} \mathrm{C}\right)$ and monosaturated and polyunsaturated TAGs like triolein $\left(0\right.$ and $\left.-5{ }^{\circ} \mathrm{C}\right)$. All these peaks tended to merge throughout the process of 

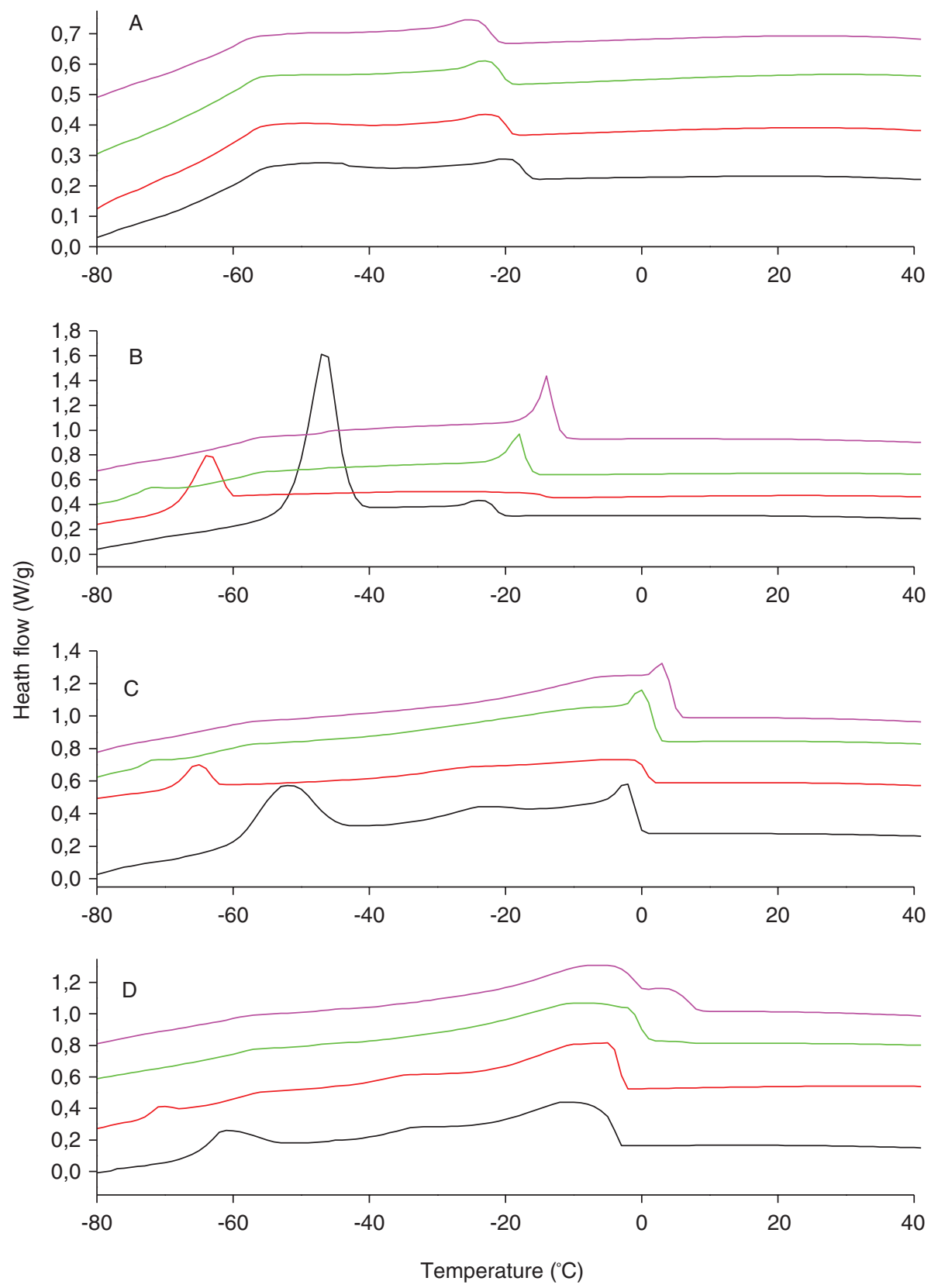

Figure 6. Crystallization curves of different sunflower oils during the process of ozonation obtained by differential scanning calorimetry. Data represent results obtained from common sunflower (A), high oleic sunflower (B), high stearic sunflower (C) and high palmitic sunflower (D). Different degrees of ozonation correspond to different colors; Initial oil (black), $0.45 \mathrm{~mol} / \mathrm{L}$ (red), $0.90 \mathrm{~mol} / \mathrm{L}$ (green) and $1,33 \mathrm{~mol} / \mathrm{L}$ (purple).

ozonation, resulting in a broad low intensity peak at the end of the process (Figure 5D). The crystallization profiles of these oils displayed a decrease in the crystallization onset, showing the decrease of the temperatures at which the secondary transitions took place. Moreover, a signal similar to that found in the high oleic, probably corresponding to triolen crystallization appeared at the same temperature and continued to decrease throughout the oxidation course (Figures 6C and 6D).
According to these results the process of ozonation is able to alter the melting profiles of the studied oils. The main effect observed is the smoothing of the profiles, involving the peak merging and widening, increasing the melting temperature and decreasing the melting enthalpies involved in the process (table 2). Furthermore, the crystallizing onset of the oils showed a steady increase due to the the effect of ozonation (table 2). This effect was depicted in previous works for other ozonized 
TABLE 2. Melting enthalpies, melting offsets and crystallization onsets from different ozonized sunflower oils

\begin{tabular}{|c|c|c|c|c|}
\hline & \multirow[b]{2}{*}{$\begin{array}{r}\text { Ozonization } \\
\text { level (mol/L) }\end{array}$} & \multicolumn{2}{|c|}{ Melting } & \multirow{2}{*}{$\begin{array}{c}\text { Cristallization } \\
\text { Onset }\left({ }^{\circ} \mathrm{C}\right)\end{array}$} \\
\hline & & $\begin{array}{c}\text { Enthalpy } \\
(\mathbf{J} / \mathbf{g})\end{array}$ & $\begin{array}{c}\text { Offset } \\
\left({ }^{\circ} \mathrm{C}\right)\end{array}$ & \\
\hline \multirow{4}{*}{$\begin{array}{l}\text { Common } \\
\text { sunflower }\end{array}$} & Initial & 64.80 & -0.9 & -15.1 \\
\hline & 0.45 & 52.61 & 4.2 & -18.4 \\
\hline & 0.90 & 32.58 & 6.3 & -19.0 \\
\hline & 1.33 & 11.91 & 7.8 & -20.0 \\
\hline \multirow{4}{*}{$\begin{array}{l}\text { High oleic } \\
\text { sunflower }\end{array}$} & Initial & 81.57 & 0.2 & -20.4 \\
\hline & 0.45 & 71.55 & 7.8 & -13.1 \\
\hline & 0.90 & 64.28 & 16.7 & -15.0 \\
\hline & 1.33 & 37.31 & 18.3 & -10.3 \\
\hline \multirow{4}{*}{$\begin{array}{l}\text { High } \\
\text { stearic } \\
\text { sunflower }\end{array}$} & Initial & 75.81 & 19.3 & 0.9 \\
\hline & 0.45 & 55.67 & 29.5 & 1.9 \\
\hline & 0.90 & 51.64 & 34.6 & 3.6 \\
\hline & 1.33 & 44.92 & 40.2 & 6.1 \\
\hline \multirow{4}{*}{$\begin{array}{l}\text { High } \\
\text { palmitic } \\
\text { sunflower }\end{array}$} & Initial & 64.98 & 21.1 & -3.0 \\
\hline & 0.44 & 49.55 & 31.8 & -1.9 \\
\hline & 0.90 & 48.89 & 38.3 & 7.9 \\
\hline & 1.33 & 44.89 & 39.0 & 9.0 \\
\hline
\end{tabular}

Data corresponded to the average of 3 determinations. Standards deviations remained below $10 \%$ of the average values.

vegetable oils (Li et al., 2013). Furthermore, the changes observed in the melting and crystallization profiles of these oils were identical to those depicted for triolein polymerization by Li et al., (2013), especially in the case of high oleic oil, the one with the highest content of that TAG. The modifications of these physical traits were concomitant with the formation of TAG condensates (Figure 3A and 3B), a process that transformed discrete TAG units into larger molecules with different physical properties. The presence of TAG dimers and oligomers hinders the regular packing of TAGs and alters the primary and secondary heath transitions. Thus, the resulting profiles at increasing ozonation levels correspond to two overlapping exotherms or endotherms corresponding to different components with different aggregation patterns, as they are individual TAGs with their corresponding oligomers. The changes induced in the oil properties by the presence of oxygenated compounds seemed to be minor if compared to these others.

\section{CONCLUSIONS}

The present work studied the changes in TAG composition and aggregation throughout the process of ozonation of different sunflower oils. The oils used in this work displayed very different TAG compositions, derived from their fatty acid composition and fatty acid distribution in the TAG backbone. The ozonation of these oils caused a rapid increment in their polar fraction, which was significantly higher in high saturated lines. The separation of neutral lipids allowed for monitoring which TAG species reacted with ozone throughout the oxidation courses. Species with higher levels of unsaturation were those more actively attacked by this oxidant, and the TAGs LLL and LLO showed the fastest reaction rate in common sunflower. The other lines showed large decreases in triolein, $\mathrm{OOO}$, with a concomitant raise of disaturated TAGs, which seemed to indicate they were especially resistant to oxidation by ozone. The formation of TAG condensates was monitored as a part of the characterization of the chemical and physical changes that take place during ozonation. In this work, the rapid formation of dimers and oligomers of TAGs during ozonation was demonstrated through a direct mechanism, which was not boundby, nor related to secondary processes like the chain reactions which are typical of autooxidation. The formation of these aggregates caused important changes in the physical properties of the oils studied, and affected their melting and crystallization profiles and enthalpies.

\section{ACKNOWLEDGEMENTS}

This work was funded by the project ICOOPCOOPB20153 from the Consejo Superior de Investigaciones Científicas (CSIC).

\section{REFERENCES}

Harwood JL, Dijkstra AJ, Gunstone FD. 2007. The lipid handbook. CRC Press. Boca Raton, FL. ISBN-13:987-0-8493-9688-5

Waltking AE, H. Wessels. 1981. Chromatographic Separation of Polar and Nonpolar Components of Frying Fats, J. Assoc. Offic. Anal. Chem. 64, 1329-1330. ISSN: 0004-5756

Choe E, Min DB. 2006. Mechanisms and factors for edible oil oxidation. Comprehensive Rev. Food Sci. Food Safety 5, 169-186. https://doi.org/10.1111/j.1541-4337.2006.00009.x

Min DB, Boff JM. 2002. Lipid oxidation of edible oil. In: Food Lipids. Chemistry, Nutrition and Biotechnology. Marcel Dekker, New York (pp. 335-364). ISBN: 0-8247-0749-4

Márquez-Ruiz G, Pérez-Camino MC, Dobarganes MC. 1990. Combination of adsorption and size-exclusion chromatography for the determination of fatty acid monomers, dimers and polymers. J. Chromatog. A. 514, 37-44. https:// doi.org/10.1016/S0021-9673(01)89374-2

Sharmin E, Zafar F, Akram D, Alam M, Ahmad S. 2015. Recent advances in vegetable oils based environment friendly coatings: A review. Ind. Crops Prod. 76, 215-229. https://doi. org/10.1016/j.indcrop.2015.06.022

Gertz C. 2000. Chemical and physical parameters as quality indicators of used frying fats. Eur. J. Lipid Sci. Technol. 102, 566-572. https://doi.org/10.1002/1438-9312(200009)102: 8/9<566::AID-EJLT566>3.3.CO;2-2

Bailey PS. 1978. Ozonation in Organic Chemistry, Volume I, Olefinic Compounds. Academic Press. New York. ISBN0120731010, 9780120731015

Díaz MF, Gavín-Sazatornil JA, Ledea O, Hernández F, Alaiz M, Garcés R. 2005. Spectroscopic characterization of ozonated sunflower oil. Ozone Sci. Eng. 27, 247-253. https://doi. org/10.1080/01919510590945822 
Martínez-Téllez G, Ledea-Lozano O, Díaz-Gómez MF. 2006. Measurement of peroxidic species in ozonized sunflower oil. Ozone Sci. Eng. 28, 181-185. https://doi.org/10.1080/ 01919510600689356

Carelli AA, Cert A. 1993. Comparative study of the determination of triacylglycerol in vegetable oils using chromatographic techniques. J. Chromatogr. A, 630, 213-222. https:// doi.org/10.1016/0021-9673(93)80458-K

Fernández-Moya V, Martínez-Force E, Garcés R. 2005. Oils from improved high stearic acid sunflower seeds. $J$. Agric. Food Chem. 53, 5326-5330. https://doi.org/10.1021/ jf0503412

Fernández-Martínez JM, Mancha M, Osorio J, Garcés R. 1997. Sunflower mutant containing high levels of palmitic acid in high oleic background. Euphytica 97, 113-116. https:// doi.org/10.1023/A:1003045726610

Garcés R, García JM, Mancha M. 1989. Lipid characterization in seeds of a high oleic acid sunflower mutant.
Phytochem. 28, 2597-2600. https://doi.org/10.1016/S0031$9422(00) 98047-6$

Li S, Bouzidi L, Narine SS. 2013. Synthesis and physical properties of triacylglycerol oligomers: examining the physical functionality potential of self-metathesized highly unsaturated vegetable oils. Ind. Eng. Chem. Res. 52, 2209-2219. https://doi.org/10.1021/ie302921h

Criegee R. 1975. Mechanism of ozonolysis. Angewandte Chemie Int. Ed. Eng. 14, 745-752. https://doi.org/10.1002/anie. 197507451

Díaz M, Gavín J, Ledea-Lozano OE, Hernández F, Alaiz M, Garcés R. 2005. Spectroscopic Characterization of Ozonated Sunflower Oil. Ozone Sci. Eng. 27, 247-253. https://doi.org/10.1080/01919510590945822

Bailey PS, Ferrell TM, Rustaiyan A, Seyhan S, Unruh LE. 1978. Stereochemistry of ozonide formation. Effects of complexing agents and rate of warm-up. J. Am. Chem. Soc. 100, 894-898. https://doi.org/10.1021/ja00471a039 